\title{
PENGARUH GAYA KEPEMIMPINAN DAN BUDAYA ORGANISASI MELALUI KEPUASAN KERJA TERHADAP KINERJA KARYAWAN DI PT. ANJUR NAULI MEDAN
}

\section{Lyandru Togumulia Tambunan}

Email : lyandru.tambunan@gmail.com

\section{Akademi Pariwisata dan Perhotelan Darma Agung}

\begin{abstract}
The objective of the research was to analyze leadership style and organizational culture on employees, satisfaction, either directly or indirectly, through employees job satisfaction as intervening variable. The research was conducted at PT. Anjur Nauli, Medan, a local company which operates in contractor service and housing development. It used descriptive quantitative and explanatory research method, supported by a survey. The population and the samples were 30 employees of PT. Anjur Nauli as the respondents. The data were gathered by conducting documentary study and distributing questionnaires and analyzed by using path analysis which consisted of direct and indirect influence. F-test was used to test the hypothesis simultaneously, and t-test for testing the hypothesis partially. The result of the hypothesis test showed that, directly, the variable of leadership style and organizational culture had positive and significant influence on employees performance. Job satisfaction as an intervening variable had positive and significant influence on employees performance. The variable of leadership style and organizational culture had positive and significant influence on employees performance through job satisfaction as intervening variable. It was also found that direct influence of leadership style and organizational culture was more significant on employees performance than through job satisfaction as intervening variable. It is recommended that the company pay attention to the factors which can increase leadership style, organizational culture, and job satisfaction because these variables will be able to increase the employees performance PT. Anjur Nauli, Medan.
\end{abstract}

Keywords : Leadership style, Organizational Culture, Employees Performance

\section{PENDAHULUAN}

Setiap perusahaan yang ingin mencapai kemajuan yang signifikan secara berkelanjutan bagaimanapun akan menempatkan hasil penelitian sebagai salah satu masukan utama dalam menentukan arah, kebijakan, dan tipe kegiatan yang dilakukan dari waktu ke waktu. Berdasarkan hasil penelitian perusahaan melaksanakan pembaharuan secara berkelanjutan dalam berbagai bidang seperti teknologi produksi, manajemen sumber daya manusia, manajemen keuangan dan lain - lain. Penelitian mampu memberikan beberapa alternatif jawaban yang memuaskan atas setiap masalah yang dihadapi organisasi baik masalah yang sedang ataupun terjadi sehingga para manajer terkait dapat memilih tindakan yang paling baik dari semua alternatif tindakan yang ada (Davis \& Cosenza, 1998, dalam Sinulingga, 2013 : 22-2). Kemudian, melihat perkembangan tren dan pertumbuhan ekonomi Sumatera Utara khususnya di bidang perumahan/real estate maka perusahaan PT.Anjur Nauli perlu 
melakukan studi yang komprehenisf, terkait pasar, produk, terutama Sumber Daya Manusia. Lebih lanjut, peneliti melihat perlu adanya penelitian mengenai pengaruh gaya kepemimpinan dan budaya organisasi terhadap kepuasan kerja karyawan, serta kinerja karyawan. Dalam hal ini kepuasan kerja sebagai variabel intervening, yang bisa mempengaruhi variabel kinerja karyawan. Diharapkan dengan penelitian ini maka perusahaan dapat memiliki pedoman dalam upaya menajga kepuasan kerja karyawan, untuk meningkatkan Kinerja Karyawan. Menurut Sinulingga (2013 : 89), Variabel Intervening adalah suatu Faktor yang secara teoritis mempengaruhi fenomena yang diobseravsi ( hubungan antara variabel independen menjadi bersifat tidak langsung) tetapi tidak dapat dilihat, diukur, ataupun dimanipulasi. Penelitian ini akan dilakukan di PT. Anjur Nauli, sebuah perusahaan yang bergerak di bidang kontraktor dan developer property, yang berlokasi diJl. Multatuli No.2, Medan. Berdasarkan uraian tersebut diatas, maka penelitian ini akan diberi judul “ Pengaruh

Gaya Kepemimpinan dan Budaya Organisasi , melalui Kepuasan Kerja, terhadap Kinerja Karyawan di PT. Anjur Nauli, Medan".

\section{RUMUSAN MASALAH}

Adapun rumusan masalah penelitian ini adalah sebagai berikut :

1. Apakah gaya kepemimpinan berpengaruh signifikan terhadap kepuasan kerja karyawan di PT. Anjur Nauli, Medan?

2. Apakah budaya organisasi berpengaruh signifikan terhadap kepuasan kerja karyawan di PT. Anjur Nauli, Medan?

3. Apakah gaya kepemimpinan berpengaruh signifikan terhadap kinerja karyawan di PT. Anjur Nauli, Medan?
4. Apakah budaya organisasi berpengaruh signifikan terhadap kinerja karyawan di PT. Anjur Nauli, Medan?

5. Apakah kepuasan kerja karyawan berpengaruh signifikan terhadap kinerja karyawan di PT. Anjur Nauli, Medan?

6. Apakah gaya kepemimpinan melalui kepuasan kerja dapat berpengaruh signifikan terhadap kinerja karyawan di PT. Anjur Nauli, Medan?

7. Apakah budaya organisasi melalui kepuasan kerja dapat berpengaruh signifikan terhadap kinerja kerja karyawan di PT. Anjur Nauli, Medan?

\section{TUJUAN PENELITIAN}

Penelitian ini bertujuan untuk mengetahui dan menganalisa :

1. Pengaruh gaya kepemimpinan terhadap kepuasan kerja Karyawan di PT. Anjur Nauli, Medan.

2. Pengaruh budaya organisasi terhadap kepuasan kerja karyawan di PT. Anjur Nauli, Medan.

3. Pengaruh gaya kepemimpinan terhadap kinerja Karyawan di PT. Anjur Nauli, Medan.

4. Pengaruh budaya organisasi terhadap kinerja karyawan di PT. Anjur Nauli, Medan.

5. Pengaruh kepuasan kerja terhadap kinerja karyawan di PT. Anjur Nauli, Medan.

6. Pengaruh gaya kepemimpinan terhadap kepuasan kerja Karyawan di PT. Anjur Nauli, Medan melalui kepuasan kerja.

7. Pengaruh budaya organisasi terhadap kepuasan kerja karyawan di PT. Anjur Nauli, Medan melalui kepuasan kerja. 


\section{MANFAAT PENELITIAN}

Manfaat yang dapat diambil dari hasil penelitian ini adalah sebagai berikut :

1. Bagi Objek Penelitian (PT. Anjur Nauli, Medan), sebagai bahan masukan dan informasi mengenai kondisi atau permasalahan sumber daya manusia perusahaan saat ini, untuk dijadikan dasar dalam upaya perbaikan dan pengembangan karyawan maupun sistem kerja yang dapat mempengaruhi kualitas pekerjaan atau kinerja karyawan.

2. Bagi institusi, diharapkan penelitian ini dapat memberikan informasi yang berharga kepada perusahaan mengenai pengelolaan SDM dan faktor-faktor apa yang dapat mempengaruhi SDM.

3. Bagi peneliti, memberikan solusi dalam pemecahan suatu masalah empiris yang didukung denga teori dan metode ilmiah yang mendukung.

4. Bagi para peneliti lain, diharapkan penelitian ini dapat menjadi referensi bagi peneliti lain yang bermaksud untuk mengkaji masalah - masalah yang berkaitan dengan penelitian seperti ini di masa yang akan datang.

\section{TINJAUAN PUSTAKA}

\section{Kinerja Karyawan}

Kinerja karyawan mengacu pada prestasi seseorang yang diukur berdasar standar dan kriteria yang ditetapkan oleh perusahaan atau organisasi. Pengelolaan untuk mencapai kinerja sumber daya manusia yang tinggi dimaksudkan guna untuk mencapai tujuan perusahaan dan juga untuk meningkatkan perusahaan secara keseluruhan ( Mas'ud, 2004 : 58).

Kinerja suatu hasil atau tingkat keberhasilan seseorang secara keseluruhan selama periode tertentu dalam melaksanakan tugas dibandingkan dengan standar hasil kerja, target, sasaran dan kriteria yang telah ditentukan terlebih dahulu dan telah disepakati bersama (Rivai, 2004 : 98). Lebih lanjut Rivai menyatakan kinerja tidak berdiri sendiri tapi berhubungan dengan kepuasan kerja dan kompensasi, dipengaruhi oleh ketrampilan, kemampuan dan sifat - sifat individu. Dengan kata lain kinerja menentukan suatu kemampuan, keinginan dan lingkungan. Oleh karena itu agar kinerja dapat berjalan dengan baik, keinginan yang tinggi harus dimiliki oleh seseorang dalam mengerjakan dan mengetahui pekerjaannya serta penyesuaian antara pekerjaan dan kemampuan dapat ditingkatkan.

\section{Gaya Kepemimpinan}

Secara harfiah kata leadership berarti adalah sifat, kapasitas dan kemampuan seseorang dalam memimpin. Menurut Yuki (2005:103), kepemimpinan merupakan proses mempengaruhi orang lain, untuk memahami dan setuju dengan apa yang perlu dilakukan dan bagaimana tugas itu dilakukan secara efektif, serta proses untuk memfasilitasi upaya individu dan kolektif untuk mencapai tujuan bersama. Menurut Definisi kepemimpinan secara luas meliputi proses mempengaruhi dalam menentukan tujuan organisasi, memotivasi perilaku pengikut untuk mencapai tujuan, mempengaruhi untuk memperbaiki kelompok dan budayanya. Selain itu, kepemimpinan juga mempengaruhi interprestasi mengenai peristiwa - peristiwa para aktivitas - aktivitas untuk mencapai sasaran, memelihara hubungan kerja sama dan kerja kelompok, perolehan dukungan dan kerja sama dari orang-orang di luar 
kelompok atau organisasi (Rivai, 2004 : 74).

\section{Budaya Organisasi}

Budaya organisasi merupakan bagian dari Manajemen Sumber Daya Manusia dan Teori Organisasi dalam rangka meningkatkan kinerja staff. Manajemen Sumber Daya Manusia melihat Budaya Organisasi diri aspek perilaku, sedangkan Teori Organisasi melihat Budaya Organisasi wadah tempat individu bekerjasama untuk mencapai tujuan, sistem nilai yang diyakini, dapat dipelajari, dapat diterapkan dan dikembangkan. dan sebaiknya perusahaan termasuk instansi pemerintahan memiliki Budaya Organisasi agar pegawai memiliki nilai - nilai, norma, acuan pedoman yang harus dilaksanakan. Selain itu Budaya organisasi juga sebagai pemersatu pegawai, peredam konflik, dan motivator pegawai untuk melaksanakan tugas dengan baik, sehingga berpengaruh positif terhadap perilaku dan kinerja pegawai. Budaya organisasional merupakan sistem makna, nilai - nilai dan kepercayaan yang dianut bersama dalam suatu organisasi yang menjadi rujukan untuk bertindak dan membedakan organisasi satu dengan organisasi lain (Mas'ud, 2004 : 44).

\section{Kepuasan kerja}

Kepuasan kerja pada tingkat tertentu dapat mencegah karyawan untuk mencari pekerjaan diperusahaan lain. Apabila karyawan di perusahaan merasa puas, karyawan cenderung akan bertahan walau tidak semua aspek-aspek perusahaan yang mempengaruhi kepuasan kerja terpenuhi. Karyawan yang memperoleh kepuasan dari perusahaannya memiliki rasa ketertarikan atau komitmen lebih besar terhadap perusahaan dibanding karyawan yang tidak puas. Dengan demikian para ahli memberikan beberapa definisi tentang kepuasan kerja.

Lima model kepuasan kerja, yang dikemukakan oleh Kreitner \& kinichi (2005:204) adalah; Pertama pemenuhan kebutuhan, model ini menjelaskan bahwa kepuasan ditentukan oleh karakteristik dari sebuah pekerjaan yang memungkinkan seseorang dapat memenuhi kebutuhannya. Kedua ketidakcocokan, model ini menjelaskan bahwa kepuasan adalah hasil dari harapan yang terpenuhi. Ketiga pencapaian nilai, model ini menjelaskan bahwa suatu pekerjaan memungkinkan untuk pemenuhan nilai-nilai kerja yang penting dari individu. Keempat persamaan, model ini kepuasan adalah suatu fungsi dari bagaimana seorang individu diperlakukan ditempat kerja. Kelima watak/genetik, model ini berusaha menjelaskan beberapa orang merasa puas dengan situasi dan kondisi kerja tertentu, namun sebagian lagi merasa tidak puas dengan kondisi tersebut.

\section{METODE PENELITIAN}

\section{Jenis dan Metode Penelitian}

Berdasarkan tingkat eksplanasi dan jenis datanya, penelitian ini menggunakan jenis penelitian deskriptif kuantitatif. Menurut Kuncoro (2005 : 79) menyatakan bahwa "Penelitian deskriptif kuantitatif meliputi pengumpulan data untuk menguji hipotesis atau menjawab mengenai status terakhir dari subjek penelitian”. Penelitian deskriptif ini bertujuan untuk menjelaskan kedudukan variabel-variabel yang diteliti serta pengaruh antara satu variabel dengan variabel yang lain. Adapun sifat dari penelitian ini adalah penelitian menjelaskan (deskriptifexplanatori) yaitu bertujuan untuk menjelaskan kedudukan variabel- 
variabel yang diteliti serta pengaruh antara satu variabel dengan variabel yang lain ( Sugiyono, 2005:79).

\section{Lokasi dan Waktu Penelitian}

Penelitian ini dilaksanakan di PT. Anjur Nauli Medan, perusahaan lokal yang bergerak di bidang property. PT. Anjur Nauli menjadi objek penelitian karena perusahaan ini adalah tempat peneliti bekerja, sehingga data lebih mudah didapat dan akan lebih akurat. Penelitian ini dimulai bulan Maret 2015 sampai November 2015.

\section{Populasi dan Sampel}

Dalam penelitian ini dikarenakan populasinya 30 orang yang berarti kurang dari 100 orang, maka diambil sampel penelitian seluruhnya sehingga dinamakan penelitian populasi. Menurut Sugiyono (2005:11) sampel yang baik adalah sampel yang representatif mewakili populasi. Berapapun jumlah anggota sampel yang akan digunakan sebagai sumber data tergantung pada tingkat kepercayaan yang dikehendaki. Jika dikehendaki sampel dipercaya $100 \%$ mewakili populasi, maka jumlah anggota sampel sama dengan jumlah anggota populasi.

\section{Jenis dan Sumber Data}

Sumber data penelitian ini diperoleh melalui dua sumber, yaitu :

\section{Data Primer}

Merupakan data yang diperoleh atau dikumpulkan langsung di lapangan. Data primer didapat dengan cara menyebarkan kuesioner yang akan dirancang sesuai dengan variabel dan indikator serta item yang ditetapkan terlebih dahulu berkaitan dengan kepemimpinan, budaya organisasi, dan kepuasan kerja. Daftar pertanyaan (questionare) yang disebarkan kepada responden dan wawancara (interview) kepada karyawan PT. Anjur Nauli Medan.

2. Data Sekunder

Data sekunder merupakan data yang diperoleh melalui pengumpulan dokumendokumen yang telah ada pada instansi tempat dilakukannya penelitian berupa data bagian departemen sumber daya manusia, yang meliputi struktur organisasi, gambaran umum perusahaan, komposisi pegawai serta bisa juga yang berasal dari literatur ataupun internet. Kemudian, data sekunder juga diperoleh melalui Studi Pustaka. Studi Pustaka merupakan suatu metode pengumpulan data yang digunakan untuk memperoleh data secara teoritis dengan mempelajari buku-buku jurnal dan referensi lain yang berkaitan dengan pembahasan penelitian ini.

\section{Metode Pengumpulan Data}

Pengumpulan data dalam penelitian ini menggunakan cara sebagai berikut :

a. Metode dokumentasi

b. Mengadakan Wawancara

c. Menyebarkan Kuesioner

Dalam penelitian ini jawaban dari pertanyaan tertutup akan diukur menggunakan skala likert. Skala likert adalah termasuk dalam skala interval dan perbedaan jawaban antara dua poin dalam skala mempunyai nilai yang sama (Sinulingga, 2013 : 162).

1. Untuk jawaban SS, yaitu Sangat Setuju diberi skor : 5 .

2. Untuk jawaban S, yaitu Setuju diberi skor : 4

3. Untuk jawaban KS, yaitu Kurang Setuju diberi skor : 3 .

4. Untuk jawaban TS, yaitu Tidak Setuju diberi skor : 2 .

5. Untuk jawaban STS, yaitu Sangat Tidak Setuju diberi skor : 1 . 


\section{VII.HASIL DAN PEMBAHASAN}

\section{Analisis Hasil Uji Statistik Kuesioner Uji Validitas}

Berdasarkan uji validitas yang telah diketahui bahwa dari jumlah pernyataan kuesioner 39 butir yang telah disebar diperoleh seluruh item pernyataan valid. Pernyataan dikatakan valid jika pada perhitungan $r_{\text {hitung }} r_{\text {tabel}}$. Dalam penelitian ini jumlah responden yang digunakan dalam menguji kualitas data adalah 30 orang sehingga untuk angka kritik rtabel yakni $0,361(\mathrm{~N}-2=30-2=28$ dengan taraf signifikansi $5 \%$ ).

\section{Uji Reliabilitas}

Berdasarkan hasil uji reliabilitas data diperoleh bahwa keseluruhan variabel penelitian telah memenuhi Alpha Cronbach's variabel penelitian sudah lebih besar dari 0,60. Berikut adalah hasil uji reliabilitas data yang disajikan dalam bentuk tabel :

\section{Tabel 1 Hasil Uji Reliabilitas} Instrumen Variabel

\begin{tabular}{lll}
\hline Variabel & $\begin{array}{l}\text { Alpha } \\
\text { Cronbach's }\end{array}$ & Ket. \\
\hline $\begin{array}{l}\text { Gaya } \\
\text { Kepemimpinan }\end{array}$ & 0,746 & reliabel \\
\hline Budaya Organisasi & 0,687 & reliabel \\
\hline Kepuasan Kerja & 0,7 & reliabel \\
\hline Kinerja Karyawan & 0,728 & reliabel \\
\hline $\begin{array}{l}\text { Sumber : Hasil Penelitian, 2015 } \\
\text { (data diolah) }\end{array}$ &
\end{tabular}

\section{Analisis Data}

\section{Uji Normalitas}

Dalam penelitian ini, uji normalitas terhadap residual dengan menggunakan uji Kolmogorov - Smirnov dan tingkat signifikansi yang digunakan $=0,05$.
Dasar pengambilan keputusan adalah melihat angka probabilitas dari statistik Kolmogorov - Smirnov, dengan ketentuan sebagai berikut.

$>$ Jika nilai probabilitas $\mathrm{p} \searrow 0,05$ maka asumsi normalitas terpenuhi.

$>$ Jika probabilitas $\mathrm{p}<0,05$ maka asumsi normalitas tidak terpenuhi.

Berikut adalah hasil uji normalitas kedua model :

Tabel 2 Hasil Uji Normalitas Struktur Model I

One - Sample Kolmogorov - Smirnov Test

\begin{tabular}{|c|c|}
\hline & $\begin{array}{l}\text { Unstandardized } \\
\text { Residual }\end{array}$ \\
\hline $\mathrm{N}$ & 30 \\
\hline Normal & .0000000 \\
\hline Parameters a,b Std.Deviation & 1.18658535 \\
\hline Most Extreme & \\
\hline Absolute & .162 \\
\hline Differences & .105 \\
\hline Negative & -.162 \\
\hline Kolmogorov - Smirnov Z & .885 \\
\hline Asymp.Sig. (2-tailed) & .414 \\
\hline \multicolumn{2}{|l|}{ a.Test distribution is Normal } \\
\hline $\begin{array}{l}\text { b.Calculated from data } \\
\text { Sumber : Hasil Penelitian, } \\
\text { Penelitian) }\end{array}$ & 15 ( Data Olahan \\
\hline
\end{tabular}


Tabel 4

Hasil Uji Multikolinieritas Struktur Model I

Coefficientsa

\begin{tabular}{|ll|l|l|}
\hline \multirow{2}{*}{ Model } & & \multicolumn{2}{l|}{ Collinearity Statistics } \\
\cline { 3 - 4 } & & Tolerance & VIF \\
\hline 1 & (Constant & & \\
& GP_X1 & .635 & 1.575 \\
& BO_X2 & .635 & 1.575 \\
\hline
\end{tabular}

a. Dependent Variable : KK_Y1

Sumber : HasilPenelitian, 2015 ( Data OlahanPeneliti)

Tabel 5

Hasil Uji Multikolinieritas Struktur Model II

Coefficientsa

\begin{tabular}{|ll|l|l|}
\hline \multirow{2}{*}{ Model } & & \multicolumn{2}{|l|}{ Collinearity Statistics } \\
\cline { 3 - 4 } & & Tolerance & VIF \\
\hline \multirow{2}{*}{1} & (Constant & & \\
& GP_X1 & .401 & 2.493 \\
& BO_X2 & .542 & 1.844 \\
& KK_Z & .359 & 2.789 \\
\hline
\end{tabular}

a. Dependent Variable : KK_Y1

Sumber : HasilPenelitian, 2015 ( Data OlahanPeneliti)

Berdasarkan hasil uji normalitas terhada kedua struktur model pada Tabel 2 dan Tabel 3 dapat dikatakan bahwa kedua struktur model telah memenuhi uji asumsi normalitas karena nilai probabilitas p.KS $\geq$ 0,05 (Asymp.Sig.). Nilai probabilitas kedua struktur model secara berurut adalah 0,414 dan 0,523 .

\section{Uji Multikolinieritas}

Dalam melihat ada atau tidaknya multikolinieritas dalam model regresi dapat dilihat dari :

1. Nilai tolerance dan lawannya.

2. Variance Inflation Factor (VIF)

Kedua ukuran ini menunjukkan setiap variabel independen manakah yang dijelaskan oleh variabel independen lainnya. Suatu model regresi menunjukkan adanya multi kolinieritas apabila nilai tolerance $<0,10$ dan VIF $\geq 10$. Pada
Tabel 3 Hasil Uji Normalitas Struktur Model II

One - Sample Kolmogorov - Smirnov Test

\begin{tabular}{|c|c|c|}
\hline & & $\begin{array}{l}\text { Unstandarsized } \\
\text { Test }\end{array}$ \\
\hline \multicolumn{2}{|l|}{$\mathrm{N}$} & 30 \\
\hline Normal & Mean & .0000000 \\
\hline \multicolumn{2}{|c|}{ Parameters a,,bStd.Deviation } & 1.00740113 \\
\hline Most Extreme & Absolute & .148 \\
\hline \multirow[t]{2}{*}{ Differences } & Positive & .148 \\
\hline & Negative & -.120 \\
\hline \multicolumn{2}{|c|}{ Kolmogorov - Smirnov Z } & .813 \\
\hline \multicolumn{2}{|c|}{ Asymp.Sig. (2-tailed) } & .523 \\
\hline
\end{tabular}

a.Test distribution is Normal

b.Calculated from data

Sumber : Hasil Penelitian, 2015 ( Data Olahan Penelitian)

penelitian ini, hasil uji multikolinieritas ditunjukkan pada tabel berikut :

Berdasarkan Tabel 4 dan 5 dapat dilihat bahwa dari kedua struktur model memiliki nilai tolerance lebih besar dari 0,10 dan VIF lebih kecil dari 10 sehingga dapat dikatakan bahwa kedua struktur model tidak mengalami gejala multikolinieritas.

\section{Uji Homoskedastisitas}

Suatu model regresi dikatakan baik apabila varians dari residual suatu pengamatan ke pengamatan lainnya adalah tetap atau disebut juga dengan homoskedastisitas dan sebaiknya akan dikatakan buruk apabila varians dari residual berbeda atau disebut dengan heteroskedastisitas dapat dilakukan dengan melihat grafik scatterplot antara nilai prediksi variabel dependen dengan residualnya. Dasar analisis yaitu :

a. Jika ada pola tertentu, seperti titik titik yang ada membentuk pola tertentu yang teratur (bergelombang, melebar kemudian menyempit) maka mengindikasikan telah terjadi heteroskedastisitas. 
Tabel 8 Hasil Uji Stimultan Struktur Model I ANOVAb

\begin{tabular}{|ll|l|l|}
\hline \multicolumn{2}{|l|}{ Model } & F \\
\hline 1 & $\begin{array}{l}\text { Regression } \\
\text { Residual } \\
\text { Total }\end{array}$ & 24.147 & $0.000 \mathrm{a}$ \\
\hline
\end{tabular}

a. Predictors : (Constant), BO_X2, GP_X1

b.Dependent Variable :

Hasil Uji Koefisien Determinasi $\left(\mathbf{R}^{2}\right)$ Struktur Sodel II HasilPenelitian, 2015 (Data Diolah) Model Summary ${ }^{b}$

\begin{tabular}{|l|l|l|l|l|}
\hline Model & $\mathrm{R}$ & $\begin{array}{l}\mathrm{R} \\
\text { Square }\end{array}$ & $\begin{array}{l}\text { Adjusted } \\
\text { Square }\end{array}$ & $\begin{array}{l}\text { Std.Error of } \\
\text { the } \\
\text { Estimate }\end{array}$ \\
\hline 1 & $.881 \mathrm{a}$ & .776 & .750 & 1.064 \\
\hline
\end{tabular}

a. Predictors : (Constant), KK_Z, BO_X2,GP_X1

b.Dependent Variable :

Kin_Y

Sumber : Hasil Penelitan, 2015 (Data

Olahan Peneliti)

b. Jika tidak ada pola yang jelas, seperti titik yang menyebar di atas dan dibawah angka 0 pada sumbu y maka tidak terjadi heteroskedastisitas.

\section{Uji Koefisien Determinasi}

Hasil uji koefision determinasi kedua struktur model dapat dilihat sebagai berikut :

Dari Tabel 6 menunjukkan bahwa nilai $\mathrm{R}^{2}$ struktur model I bernilai 0,641 atau 64,1 \%. Artinya, nilai presentasi Gaya Kepemimpinan $\left(\mathrm{X}_{1}\right)$ dan Budaya Organisasi $\left(\mathrm{X}_{2}\right)$ dalam menjelaskan pergerakan Kepuasan Kerja ( $\left.\mathrm{Y}_{1}\right)$ adalah $64,1 \%$ sisanya 35,9 \% adalah faktor faktor lain yang tidak disebutkan dalam penelitian ini.

Untuk struktur model II mempunyai nilai R2 0,776 atau $77,6 \%$. Artinya, nilai presentasi Gaya Kepemimpinan $\left(\mathrm{X}_{1}\right)$, Budaya Organisasi $\left(\mathrm{X}_{2}\right)$ dan Kepuasan Kerja (Y1) dalam menjelaskan pergerakan
Kinerja Karyawan (Y2) adalah 77,6 \% sisanya $22,4 \%$ adalah faktor-faktor lain yang tidak disebutkan dalam penelitian ini.

\section{Uji Stimultan}

Dalam penelitian ini, tingkat signifikansi yang digunakan adalah $5 \%(0,05)$. Hasil uji signifikansi adalah sebagai berikut :

Tabel 6

Hasil Uji Koefisien Determinasi $\left(\mathbf{R}^{2}\right)$ Struktur Model I

\begin{tabular}{|c|c|c|c|c|}
\hline \multicolumn{5}{|c|}{ Model Summary ${ }^{b}$} \\
\hline Model & $\mathrm{R}$ & $\begin{array}{l}\mathrm{R} \\
\text { Square }\end{array}$ & $\begin{array}{ll}\text { Adjusted } & \mathrm{R} \\
\text { Square } & \end{array}$ & $\begin{array}{l}\text { Std.Error of } \\
\text { the Estimate }\end{array}$ \\
\hline 1 & $.801 \mathrm{a}$ & .641 & .615 & 1.230 \\
\hline \multicolumn{5}{|c|}{ 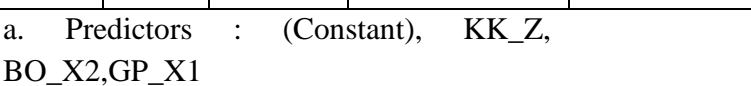 } \\
\hline \multicolumn{5}{|c|}{$\begin{array}{l}\text { b.Dependent Variable : } \\
\text { Kin_Y }\end{array}$} \\
\hline \multicolumn{5}{|c|}{$\begin{array}{l}\text { Sumber : HasilPenelitan, } 2015 \text { (Data } \\
\text { OlahanPeneliti) }\end{array}$} \\
\hline
\end{tabular}

Tabel 9 Hasil Uji Stimultan Struktur Model II

ANOVAb

\begin{tabular}{|c|c|c|c|}
\hline \multicolumn{2}{|c|}{ Model } & \multicolumn{2}{|c|}{ F $\quad$ Sig. } \\
\hline 1 & $\begin{array}{l}\text { Regression } \\
\text { Residual } \\
\text { Total }\end{array}$ & 30.047 & $.000 \mathrm{a}$ \\
\hline \multicolumn{4}{|c|}{$\begin{array}{l}\text { a.Predictors : (Constant), KK_Z, BO_X2,GP_X1 } \\
\text { b.Dependent Variable : Kin_y }\end{array}$} \\
\hline
\end{tabular}

Dari Tabel 8 dapat dikatakan bahwa pengaruh Gaya Kepemimpinan $\left(\mathrm{X}_{1}\right)$ dan Budaya Organisasi $\left(\mathrm{X}_{2}\right)$ terhadap Kepuasan Kerja (Y1) signifikan secara serempak karena nilai sig.-F $(0,000)$ lebih kecil dari 0,05 . Untuk struktur model II pada tabel 9 juga memenuhi uji serempak atau uji-f karena nilai sig.-F $(0,000)$ lebih kecil dari 0,05 . Dengan kata lain, pengaruh Gaya Kepemimpinan $\left(\mathrm{X}_{1}\right)$, Budaya Organisasi $\left(\mathrm{X}_{2}\right)$ dan Kepuasan Kerja (Z) terhadap Kinerja Karyawan (Y) signifikan secara serempak. 


\section{Uji Parsial}

Variabel independen dikatakan mempunyai pengaruh yang signifikan terhadap variabel dependen apabila nilai prob. (t-statistic) lebih besar dari tingkat signifikansi yang

Tabel 10 Hasil Uji Parsial Struktur Model I

Coefficientsa

\begin{tabular}{|l|l|l|l|l|}
\hline \multirow{2}{*}{ Model } & \multicolumn{2}{|l|}{$\begin{array}{l}\text { Unstandardized } \\
\text { Coefficients }\end{array}$} & \multirow{2}{*}{ Sig. } \\
\cline { 2 - 5 } & $\mathrm{B}$ & Std.Error & $\mathrm{T}$ & .031 \\
\hline $\begin{array}{l}\text { GP_X1 } \\
\text { (Constant) }\end{array}$ & 10.085 & 4.425 & 2.279 & .000 \\
BO_X2 & .563 & .142 & 3.969 & .041 \\
\hline
\end{tabular}

a. Dependent Variable

: KK_Z

Sumber : Hasil Penelitian, 2015 (Data Olahan

Peneliti)

digunakan. Berikut adalah hasil uji parsial (uji-t) dari kedua struktur model :

\section{Tabel 11 Hasil Uji Parsial Struktur Model I}

Coefficientsa
\begin{tabular}{|r|l|l|l|l|}
\hline \multirow{2}{*}{ Model } & \multicolumn{2}{l|}{$\begin{array}{l}\text { Unstandardized } \\
\text { Coefficients }\end{array}$} & & \\
\cline { 2 - 4 } & $\mathrm{B}$ & Std.Error & $\mathrm{t}$ & Sig. \\
\hline 1 & & & .978 & .337 \\
(Constant) & 4.090 & 4.181 & .978 \\
GP_X1 & .390 & .154 & 2.525 & .018 \\
BO_X2 & .248 & .115 & 2.163 & .040 \\
KK_Z & .375 & .167 & 2.250 & .033 \\
\hline
\end{tabular}

a. Dependent Variable :

KK_Z

Sumber : Hasil Penelitian, 2015 (Data Olahan

Peneliti

Berdasarkan Tabel 10 dan Tabel 11 dapat dilihat bahwa secara parsial keseluruhan pengaruh variabel independen yakni Gaya Kepemimpinan $\left(\mathrm{X}_{1}\right)$, Budaya Organisasi $\left(\mathrm{X}_{2}\right)$ dan variabel intervening Kinerja Karyawan (Y1) karena nilai probabilitas $\mathrm{t}$ lebih kecil dari tingkat signifikansi yang digunakan yakni $5 \%$ atau 0,05 sehingga dapat dikatakan bahwa Kinerja Karyawan secara tidak langsung mampu sebagai variabel intervening antara hubungan variabel independen dan dependen.

\section{Pengaruh Langsung. Tidak Langsung dan Total Pengaruh}

Berikut adalah nilai pengaruh langsung, tidak langsung dan total pengaruh yang disajikan dalam bentuk tabel :

\begin{tabular}{|c|c|c|c|c|}
\hline $\begin{array}{l}\text { Bentuk } \\
\text { Pengaruh }\end{array}$ & $\begin{array}{l}\text { Variabel } \\
\text { Penelitian }\end{array}$ & $\begin{array}{l}\text { GK } \\
(\mathrm{X} 1)\end{array}$ & $\begin{array}{l}\text { BO } \\
\mathrm{X} 2)\end{array}$ & $\mathrm{KK}(\mathrm{Z})$ \\
\hline \multirow{2}{*}{ Langsung } & $\begin{array}{l}\text { Kepuasan } \\
\text { Kerja (Z) }\end{array}$ & 0,563 & 0,263 & 0 \\
\hline & $\begin{array}{l}\text { Kinerja } \\
\text { Karyawan }\end{array}$ & 0,39 & 0,248 & 0,375 \\
\hline
\end{tabular}

\begin{tabular}{|c|c|c|c|c|}
\hline \multirow{2}{*}{$\begin{array}{l}\text { Tidak } \\
\text { Langsung }\end{array}$} & $\begin{array}{l}\text { Kepuasan } \\
\text { Kerja (Z) }\end{array}$ & 0 & 0 & 0 \\
\hline & $\begin{array}{l}\text { Kinerja } \\
\text { Karyawan } \\
(\mathrm{Y})\end{array}$ & 0,211 & 0,099 & 0 \\
\hline \multirow{2}{*}{$\begin{array}{l}\text { Total } \\
\text { Pengaruh }\end{array}$} & $\begin{array}{l}\text { Kepuasan } \\
\text { Kerja (Z) }\end{array}$ & 0,563 & 0,263 & 0 \\
\hline & $\begin{array}{l}\text { Kinerja } \\
\text { Karyawan } \\
\text { (Y) }\end{array}$ & 0,601 & 0,347 & 0,375 \\
\hline
\end{tabular}

VIII. PEMBAHASAN

\section{Pengaruh Gaya Kepemimpinan terhadap Kepuasan Kerja}

Berdasarkan hasil analisis pada uji parsial (uji-t) diperoleh bahwa Gaya Kepemimpinan mempunyai nilai prob. $t$ statistic 0,0000 lebih kecil dari 0,05 maka 
dapat dikatakan bahwa pengaruh Gaya Kepemimpinan secara langsung terhadap Kepuasan Kerja signifikan sehingga $\mathbf{H}_{1}$ : Gaya kepemimpinan berpengaruh positif signifikan terhadap kepuasan kerja Karyawan di PT.Anjur Nauli,Medan diterima. Hal ini juga diperoleh Cetin et al. (2012) yang dalam penelitiannya menyimpulkan bahwa Gaya Kepemimpinan dan Kompetensi Komunikasi memiliki pengaruh signifikan terhadap Kepuasan Kerja. Lebih lanjut lagi, Elkordy (2013) menyimpulkan bahwa Kepemimpinan Transformasional perpengaruh positif signifikan terhadap Kepuasan Kerja dan Komitmen Organisasi.

\section{Pengaruh Budaya Organisasi terhadap Kepuasan Kerja}

Budaya Organisasi mempunyai nilai prob. t-statistic 0,041 lebih kecil dari 0,05 maka dapat dikatakan bahwa pengaruh Budaya Organisasi terhadap Kepuasan Kerja signifikan sehingga $\mathbf{H}_{2}$ : Budaya Organisasi berpengaruh positif signifikan terhadap kepuasan kerja karyawan di PT.Anjur Nauli,Medan diterima. Peneliti terdahulu yaitu Widono (2012) dalam penelitiannya juga menyimpulkan bahwa secara stimultan dan parsial variabel motivasi, gaya kepemimpinan dan budaya organisasi berpengaruh positif signifikan terhadap Kinerja Karyawan.

\section{Pengaruh Gaya Kepemimpinan terhadap Kinerja Karyawan}

Gaya kepemimpinan mempunyai nilai prob.t-statistic 0,018 lebih kecil dari 0,05 maka dapat dikatakan bahwa pengaruh Gaya Kepemimpinan secara langsung terhadap Kinerja Karyawan signifikan. Dengan kata lain, H3: Gaya
Kepemimpinan berpengaruh positif signifikan terhadap kinerja karyawan di PT.Anjur Nauli, Medan dapat diterima. Hasil ini juga sama dengan hasil peneliti terdahulu yakni Mariam (2009) menyimpulkan bahwa Gaya Kepemimpinan berpengaruh positif signifikan terhadap kepuasan kerja dan kinerja pegawai.

\section{Pengaruh Budaya Organisasi terhadap Kinerja Karyawan}

Budaya Organisasi mempunyai nilai prob.tstatistic 0,040 lebih kecil dari 0,05 maka dapat dikatakan bahwa pengaruh Budaya Organisasi (X2) secara langsung terhadap Kinerja Karyawan (Y) signifikan. Dengan kata lain, $\mathbf{H}_{4}$ : Budaya Organisasi berpengaruh positif signifikan terhadap kinerja karyawan di PT.Anjur Nauli, Medan dapat diterima. Peneliti terdahulu yaitu Widono (2012) dalam penelitiannya juga menyimpulkan bahwa secara stimultan dan parsial variabel motivasi, gaya kepemimpinan dan budaya organisasi beroengaruh positif signifikan terhadap kinerja Pegawai Kecamatan Banyakan Kabupaten Kediri.

\section{Pengaruh Kepuasan Kerja terhadap Kinerja Karyawan}

Kepuasan kerja mempunyai nilai prob.tstatistic 0,033 lebih kecil dari 0,05 maka dapat dikatakan bahwa pengaruh Kepuasan Kerja secara langsung terhadap Kinerja Karyawan signifikan maka $\mathbf{H}_{5}$ : Kepuasan Kerja berpengaruh positif signifikan terhadap kinerja karyawan di PT.Anjur Nauli, Medan dapat diterima. Hasil yang sama juga diperoleh Satyawati dan Suartana pada penelitian sebelumnya yang menyatakan bahwa kepuasan kerja sebagai variabel intervening berpengaruh positif terhadap kinerja keuangan. Selain 
Satyawati dan Suartana, Indrawati (2013) dalam penelitiannya juga menyatakan bahwa kepuasan kerja memiliki pengaruh signifikan yang positif terhadap kinerja karyawan.

\section{Pengaruh Gaya Kepemimpinan melalui Kepuasan Kerja terhadap Kinerja Karyawan}

Pengaruh Gaya Kepemimpinan terhadap Kinerja Karyawan melalui Kepuasan Kerja adalah hasil kali antara koefisien jalur dari $\mathrm{X}_{1}$ ke $\mathrm{Y} 1$ danY1 ke Y2 yakni 0,563 x 0,375 $=0,211$ sehingga $\mathbf{H}_{6}:$ Gaya Kepemimpinan berpengaruh positif signifikan melalui Kepuasan Kerja terhadap Kinerja Karyawan di PT. Anjur Nauli, Medan diterima.

\section{Pengaruh Budaya Organisasi terhadap Kinerja Karyawan melalui Kepuasan Kerja}

Pengaruh Budaya Organisasi $\left(\mathrm{X}_{2}\right)$ terhadap Kinerja Karyawan (Y) melalui Kepuasan Kerja (Z) adalah hasil kali antara koefisen jalur dari $\mathrm{X}_{2}$ ke $\mathrm{Y} 1$ dan $\mathrm{Y} 1 \mathrm{ke} \mathrm{Y} 2$ yakni $0,263 \times 0,3750=0,99$ sehingga $\mathbf{H}_{7}$ : Budaya Organisasi berpengaruh positif signifikan melalui Kepuasan Kerja terhadap Kinerja Karyawan di PT.Anjur Nauli, diterima. Hasil ini sesuai dengan hasil penelitian dari Mariam, Rani (2009) di PT. Asuransi Jasa Indonesia, hasil penelitian menunjukkan budaya organisasi dan gaya kepemimpinan mempunyai pengaruh positif signifikan terhadap kepuasan kerja dalam meningkatkan kinerja karyawan.

\section{KESIMPULAN}

Berdasarkan hasil penelitian maka kesimpulan penelitian yang diperoleh adalah sebagai berikut:
1. Gaya

Kepemimpinan Transformasional berpengaruh positif dan signifikan terhadap Kepuasan Kerja Karyawan di PT.Anjur Nauli, Medan.

2. Budaya Organisasi berpengaruh positif dan signifikan terhadap Kepuasan Kerja Karyawan di PT.Anjur Nauli,Medan.

3. Gaya

Kepemimpinan Transfomasional secara langsung maupun tidak langsung berpengaruh positif dan signifikan terhadap Kinerja Karyawan di PT.Anjur Nauli, Medan.

4. Budaya Organisasi secara langsung maupun tidak langsung berpengaruh positif dan signifikan terhadap Kinerja Karyawan di PT.Anjur Nauli,Medan

5. Kepuasan Kerja berpengaruh positif dan signifikan terhadap Kinerja Karyawan di PT.Anjur Nauli, Medan. Secara menyeluruh, Gaya Kepemimpinan memiliki pengaruh yang lebih besar terhadap Kepuasan Kerja maupun Kinerja Karyawan dibandingkan dengan Budaya Organisasi.

6. Gaya Kepemimpinan berpengaruh positif dan signifikan terhadap Kinerja Karyawan melalui variabel intervening Kepuasan Kerja.

7. Budaya Organisasi memiliki pengaruh yang positif dan signifikan terhadap kinerja karyawan, melalui kepuasan kerja sebagai variabel intervening.

\section{DAFTAR PUSTAKA}

Cetin, M., M.E. Karabay and M.N.Efe.2012. The Effects of Leadership Styles and the Communication Competency of Bank Managers on the Emploee's Job Satisfaction : The Case of Turkish 
Banks. Procedia - Social and Behavioral Sciences $58: 227-235$.

Elkordy, M. 2013. Transformational Leadership and Organizational Culture as Predictors of Employees Attitudinal Outcomes. Business Management Dynamics, Vol. 3 (5) : 15 - 26.

Indrawati, A.D. 2013. Pengaruh Kepuasan Kerja terhadap Kinerja Karyawan dan Kepuasan Pelanggan pada Rumah Sakit Swasta di Kota Makassar. Jurnal Manajemen, Strategi Bisnis, dan Kewirausahaan, Vol. 7(2) : 135 - 142.

Kreitner dan Kinicki. 2005. Perilaku Organisasi. Jakarta : Salemba Empat.

Kreitner, Robert dan Knicki Angelo. 2003. Perilaku Organisasi, Terjemahan Erly Suandy. Edisi Pertama. Jakarta : Salemba Empat.

Kuncoro, Mudrajad. 2005.Metode Kuantitatif : Teori dan Aplikasi Untuk Bisnis dan Ekonomi. Unit Penerbit dan Percetakan YKPN. Yogyakarta.

Mariam, R. 2009. Pengaruh Kepemimpinan dan Budaya Organisasi terhadap Kinerja Karyawan dengan Kepuasan Kerja sebagai Variabel Intervening, Studi pada Kantor Pusat PT.Asuransi Jasa Indonesia (Perserp). Tesis.Program Studi Magister Manajemen, Program Pascasarjana, Universitas Dipnegoro. Semarang.

Mas'ud, Fuad.2004. Survai Diagnosis Organisasional Konsep dan Aplikasi. Semarang : Badan Penerbit (BP) UNDIP.

Riva'i H. Veithzal. 2011. Manajemen Sumber Daya Manusia untuk Perusahaan, dari Teori ke Praktek. Raja Grafindo Persada. Jakarta.
Robbins, Stephen P. 2006. Perilaku Organisasi. Edisi Kesepuluh. Jakarta : PT. Indeks Kelompok Gramedia.

Sinulingga, Sukaria. 2013. Metode Penelitian. USU Press. Medan

Sugiyono, 2005. Metode Penelitian Bisnis. Cetakan Kedelapan. Penerbit CV. Alfabeta. Bandung.

Widono, S. 2012. Pengaruh Motivasi, Gaya Kepemimpinan dan Budaya Organisasi terhadap Kinerja Pegawai Kecamatan Banyakan Kabupaten Kediri. Jurnal Ilmu Manajemen, REVITALISASI, Vol.1 (30 : 133 - 144.

Yuki, G. 2005 Kepemimpinan Dalam Organisasi. Edisi Kelima. Jakarta : PT Indeks. 